\title{
Young adults and the 5 a day campaign: perceived benefits and barriers of eating more fruits and vegetables
}

Article

Accepted Version

Herbert, G., Kennedy, O., Lobb, A. and Butler, L. (2010) Young adults and the 5 a day campaign: perceived benefits and barriers of eating more fruits and vegetables. International Journal of Consumer Studies, 34 (6). pp. 657-664. ISSN 14706423 doi: https://doi.org/10.1111/j.1470-6431.2010.00872.x Available at https://centaur.reading.ac.uk/8138/

It is advisable to refer to the publisher's version if you intend to cite from the work. See Guidance on citing.

To link to this article DOI: http://dx.doi.org/10.1111/j.1470-6431.2010.00872.x

Publisher: Wiley-Blackwell

All outputs in CentAUR are protected by Intellectual Property Rights law, including copyright law. Copyright and IPR is retained by the creators or other copyright holders. Terms and conditions for use of this material are defined in the End User Agreement.

www.reading.ac.uk/centaur 
Central Archive at the University of Reading

Reading's research outputs online 
Title: Young UK adults and the 5 A DAY campaign: perceived benefits and barriers of eating more fruits and vegetables

Short title: Young adults and the 5 A DAY campaign

Authors:

Georgia Herbert (Corresponding author)

School of Psychology and Clinical Language Sciences

University of Reading

Early Gate

Whiteknights

PO Box 238

Reading

RG6 6AL

UK

Email: g.herbert@ reading.ac.uk

Dr Laurie Butler

School of Psychology and Clinical Language Sciences

University of Reading

Earley Gate

Whiteknights

PO Box 238

Reading

RG6 6AL

UK

Dr Orla Kennedy

Hugh Sinclair Human Nutrition Group

School of Chemistry, Food Biosciences \& Pharmacy

University of Reading

PO Box 226

Reading

RG6 6AP

UK

Dr Alexandra Lobb

Department of Agricultural \& Food Economics

University of Reading

PO Box 237

Reading

RG6 6AR

UK 


\section{Abstract}

Although consuming adequate amounts of fruit and vegetables reduces the risk of developing chronic diseases, it is widely recognised that young adults' intakes are currently well below the Department of Health's recommended five portions a day, with men consuming even less than women. One approach in the UK has been to introduce health campaigns such as the 5 A DAY programme, however little is currently known about how well their messages are understood amongst young adults. This study examined current knowledge of the 5 A DAY message in young adults, as well as the perceived benefits and remaining barriers towards consuming more fruit and vegetables. In total, four focus groups were conducted using male $(n=22)$ and female $(n=18)$ students at the University of Reading. Content analysis revealed that while participants were aware of the 5 A DAY recommendation, there was widespread confusion regarding the detail. In addition, men were less accepting of the message than women, reporting greater disbelief and a lack of motivation to increase intake. Finally, a range of barriers was reported by participants of both genders, despite the perceived beneficial effects for health and appearance. The results illustrate a considerable gap between awareness and knowledge of the 5 A DAY message, and underscore the challenge that changing behaviour in young adults represents. As well as stepping up education and skill-based health campaigns, more targeted gender specific interventions will be needed to achieve sustained increases in fruit and vegetable intake.

Keywords: fruit and vegetables; 5 A DAY; gender; young adults; focus groups 


\section{Introduction}

Current scientific evidence provides a compelling case that a diet high in fruit and vegetables significantly reduces the risk of a wide range of diseases, including coronary heart disease, stroke and certain forms of cancer (Joshipura et al., 2001; World Cancer Research Fund/American Institute for Cancer Research, 2007). As such, most dietary guidelines recommend that adults should consume at least five portions (defined as $400 \mathrm{~g}$ ) of a variety of fruit and vegetables every day (World Health Organisation, 2003). However, those from the UK and other northerly European countries such as Scandinavia and the Netherlands are less likely to meet this recommendation than those from more southerly countries such as Greece and Spain (Naska et al., 2000; Agudo et al., 2002). This recommendation has therefore formed the backdrop to a number of health campaigns, including the 5 A DAY programme in England introduced by the Department of Health in 2002. Having knowledge of the number of recommended portions for health benefits is thought to be a key factor in determining fruit and vegetable intake (KrebsSmith et al., 1995). Therefore, it is encouraging that $78 \%$ of consumers in a recent survey commissioned by the Food Standards Agency in the UK could correctly name the number of portions of fruit and vegetables that they should try to eat every day, up from $43 \%$ when first measured in 2000 (Food Standards Agency, 2008). Unfortunately, epidemiological data suggests that this increase in awareness has not been accompanied by similar changes in behaviour, with the Food Standards Agency noting little change in the number of UK adults claiming to eat five or more portions between 2000 (26\%) and 2005 (30\%) (Food Standards Agency, 2007). Of particular concern to health professionals is that fruit and vegetable consumption is so low among young adults, a group that has grown up with the benefits of dietary recommendations and might therefore be expected to have diets that most reflect this. For example, the Health 
Survey for England reported that young men and women (16-24 years old) consumed an average of 2.9 and 3.2 portions of fruit and vegetables per day respectively (Joint Health Surveys Unit, 2008). This age group is characterized by non-optimal behaviours such as skipping meals, especially breakfast, (Nicklas et al., 1998) with their dietary intake often consisting of ready meals and fast food ensuring an unbalanced diet, high in fat, sodium and energy with minimal intakes of fibre and calcium (Georgiou et al., 1997).

As young adulthood is regarded as a transitional period to self-sufficiency, (Howarth, 1991) it is a good point to target interventions designed to promote healthier living. However, before effective interventions can be designed, more needs to be known about the apparent disparity between knowledge and behaviour. A number of previous qualitative studies have explored underlying attitudes and barriers towards eating fruit and vegetables amongst adults (Eisner et al., 1992; Anderson et al., 1994b; Murphy and Segan, 1994; Reicks et al., 1994; Brug et al., 1995; Marshall et al., 1995; Treiman et al., 1996; Balch et al., 1997; Hampl and Sass, 2001; Paisley et al., 2001; Dixon et al., 2004; John and Ziebland, 2004; Lea et al., 2005; Paisley and Skrzypczyk, 2005; Kamphuis et al., 2007). However, most of these studies were not carried out in the UK, almost all pre-date the introduction of the 5 A DAY programme and only one focused specifically on young adults (under 35 year olds). Worryingly, Murphy and Segan (1994) reported that Australian young adults doubted the need to increase their vegetable consumption even when evident that they were not consuming the recommended amount. An important, but unknown question is therefore whether similar attitudes are prevalent in UK young adults despite the introduction of the 5 A DAY message.

The primary aim of the present study therefore is to explore the impact that the 5 A DAY programme has had on young adults awareness and understanding of current healthy eating 
guidelines. One likely outcome is that understanding of the content of the 5 A DAY message lags well behind awareness of its existence.

In light of the introduction of the 5 A DAY message, a secondary aim is to identify what young adults see as the benefits and remaining barriers to consuming fruit and vegetables. Due to the reported disparity in consumption of fruit and vegetables in men and women (Joint Health Surveys Unit, 2008), these will be explored separately as a function of gender, as the underlying behavioural determinants may be different. Such a fine-grained approach is warranted as previous work (Buttriss et al., 2004) has shown that communication initiatives may be more effective if designed for specific groups.

\section{Method}

A sample ( $\mathrm{n}=40)$ of young adults $(18-24$ years old) studying non-nutrition/food related degrees at the University of Reading were used for this study. They were offered course credits or $£ 5$ remuneration for their time and effort spent on the study. Over half of the participants (57.5\%) lived in student hall accommodation, whereas the rest lived in private accommodation (42.5\%).

Four semi-structured focus group were undertaken on university premises. Focus groups one and two were conducted with female participants $(n=10$ and $n=8)$ and three and four with males ( $n=10$ and $n=12$ ). The focus group discussions followed a semi-structured interview guide which was developed following a review of the existing literature and discussion between the authors. The guide was designed to explore participants' awareness and understanding of the 5 A DAY message and the perceived benefits and barriers to the consumption of fruit and vegetables. The exact way in which the questions were addressed during the focus groups depended on the progress of the discussion. Although most issues were naturally covered during the course of 
each focus group, if an issue was not addressed the moderator would ask a question to steer the participants towards the issue once the current discussion had stopped revealing new data. In each focus group, the participants were first asked about their consumption of fruit and vegetables as a starting point for further discussion.

The focus groups took place in a meeting room in the Department of Psychology, at the University of Reading. As participants arrived, nametags were distributed and introductions were made to familiarise the participants with the moderators and the rest of the group. Each discussion lasted on average one and a half hours which included completion of a short demographic and lifestyle questionnaire. The moderator used non-directive prompts and probing questions to encourage discussion while a second researcher took supplementary notes.

Discussions were taped, transcribed verbatim with the additional aid of the second researcher's notes and then analysed using content analysis methods by two experienced researchers who agreed themes. The use of the qualitative software package Atlas Ti (Version 5.2 scientific software development gmbh, Berlin) allowed for easier storage and retrieval of data. Those themes that had been discussed at the greatest length by at least $50 \%$ of participants within a single focus group or by 1 or more participant across different groups were identified as the most important.

Ethical approval for the study was gained from the University of Reading Ethics and Research Committee.

\section{Results}

The results will be discussed with reference to 3 main questions: (1) How well is the 5 A DAY message understood? (2) What are the perceived benefits of eating fruit and vegetables? (3) 
What remaining barriers prevent young adults from eating more fruit and vegetables? In each case, the main themes that emerged including any gender differences will be reported.

\section{How Well is the 5 A DAY Message Understood?}

Self reported behaviour. Analysis of the preliminary lifestyle questionnaire revealed that male participants reported consuming an average of 1.8 portions of fruit and vegetables over the past 24 hours compared to females who consumed three portions. Only $4.5 \%$ of males and $16.7 \%$ of females claimed to have consumed the recommended five portions in the previous 24 hours. These figures were consistent with verbal statements made by participants during the focus groups themselves. Specifically, the majority of participants reported consuming around two to three portions of fruit and vegetables a day, with males more likely than females to say that they rarely consumed fruit or vegetables at all.

Knowledge and awareness. All participants across the 4 focus groups were aware of the recommendation to consume five portions of fruit and vegetables per day. However, there was broad consensus among participants of both genders that the term 'portion' was ambiguous and difficult to interpret. The Department of Health advices that a portion is equal to 80 grams and they have defined how much of each fruit and vegetable constitutes this amount e.g. 14 cherries, two kiwi fruits and half a pepper each equal a portion (Department of Health, 2007). While participants were aware that one apple and one banana constituted a portion, there was more often confusion over what constituted a portion size of other fruits and vegetables.

It's a real hand waving gesture. When you say a portion, is that two thirds of a courgette or a whole courgette. I don't know. [Focus group 3, male] 
Great uncertainty arose when it came to defining portion sizes of smaller fruits or vegetables e.g. grapes, strawberries or peas.

I don't know with the small ones, I don't know how much they are supposed to be. [Focus group 2, female]

There was also a lack of understanding in both males and females as to what could legitimately count towards the 5 A DAY target. Although the Department of Health guidelines suggest that a $150 \mathrm{ml}$ serving of $100 \%$ fruit juice and three heaped tablespoons of pulses or beans including baked beans can each count as 1 of your 5 A DAY, participants were unsure about this information. Furthermore potatoes are considered a 'starchy' food and so do not count as a portion, however this was another piece of information that participants misunderstood.

It depends what you do with it [potatoes]. Like if you fry it, then it counts as a treat, where as if you boil it or if you roast it I think it would still count. [Focus group 3, male] The Department of Health suggests that to get the maximum health benefits, your 5 A DAY should consist of a variety of fruit and vegetables as they all contain different combinations of fibre, vitamins, minerals and other nutrients (Williams, 1995). When discussing the 5 A DAY recommendation however, participants, especially males, displayed a lack of awareness that this message also necessitates variety.

... even if you've gone off and eaten a load of Indian takeaways and mars bars but you can still say I've had my five apples. [Focus group 3, male]

Even on occasions where there was some appreciation of the need for variety, the requirement for a balance of fruit and vegetables was not understood. 
So I think it's about changing what you do eat and mixing it about a bit so some days eating, maybe if it's just different kinds of fruit you can probably get away with that. There's loads of different types of fruit. [Focus group 4, male]

Message acceptance. Of particular concern in the male focus groups was the widespread view that increasing fruit and vegetable intake was unnecessary despite the fact that self reported intakes were currently well under recommended levels.

It's hard to go out and buy fruit and vegetables when we're functioning now. So what would make us go out and buy a load of fruit and veg now, there's no incentive to. [Focus group 4, male]

Males also reported disbelief towards the benefits of consuming five portions of fruit and vegetables a day.

I mean if you're used to the way you eat and you don't eat five fruit and veg a day and you feel all right, you're not going to change it just cos the Government says five is what you should be eating. You're going to say, I'm alright, until you end up in hospital.

[Focus group 4, male]

Finally, a lack of motivation towards eating fruit and vegetables was also prevalent amongst both male focus groups.

If it's there I'll eat it but I just can't be bothered to go and buy it. [Focus group 4, male] It is noteworthy that a lack of perceived need, lack of motivation, and disbelief towards the fruit and vegetable recommendation were not expressed by the female cohort. Generally speaking, females instead were more accepting of the message with some striving to consume more fruit and vegetables to reach five portions a day. 


\section{What are the Perceived Benefits of Eating Fruit and Vegetables?}

Young adults expressed two major benefits with respect to consuming fruit and vegetables. The first concerned the health benefits of eating fruit and vegetables and was mentioned by both male and female participants. The second concerned the benefits that consuming fruit and vegetables have on appearance, and was only referred to in the female focus groups.

Health. The potential health benefits of eating fruit and vegetables were recognised by participants of both genders. This is perhaps surprising in light of doubts raised by male participants as regards the specific benefits to themselves of eating 5 portions of fruit and vegetables a day. Fruit and vegetables were considered healthy because of their high fibre content which aided digestion, as well as their large vitamin content. The following view was typical of those expressed in the focus groups.

I don't like lettuce but I always eat it because it's healthy like all the greens. [Focus group 2 , female]

Males, like females, mentioned the disease prevention qualities that fruit and vegetables possess, although males were less specific and displayed greater confusion as to their worth.

Appearance. Female participants alone expressed the belief that consuming fruit and vegetables positively enhanced their appearance, specifically in terms of improving their skin and aiding weight loss.

It's good for your skin as well. [Focus group 2, female] 
Well for me, it's because I'm trying to lose weight, so if I have vegetables or fruit instead of something like junk food I'll be able to reach my target than if I eat junk. [Focus group 2 , female]

\section{What Remaining Barriers Prevent Young Adults from Eating More Fruit and Vegetables?}

In terms of understanding the relatively poor uptake of fruit and vegetables in young adults, six major barriers emerged from the current focus groups; living circumstances, cost, time/convenience, cooking skills, sensory issues and planning skills.

Living circumstances. Interestingly, while both living at home and out of halls were reported as facilitators to consuming fruit and vegetables, living in catered student accommodation was viewed as a barrier primarily due to a perceived lack of variety.

Yeah, when you come out of [university] halls you can be more and more healthy as I can eat the fruit and vegetables I like, rather than, I mean halls decides what fruit and vegetables they are going to sell and it's not necessarily what you're used to or want.

[Focus group 1, females]

However, after a review of the catering choices, this lack of variety may be a perception rather than an actual environmental barrier. Furthermore there was an acknowledgement that additional opportunities to obtain fruit and vegetables were increasingly available in retail outlets in and around the university.

I think it's been made easier more recently because they're sort of encouraging people to eat more, like more packets of fruit around campus and stuff you can buy and you can fit more portions in. [Focus group 2, females] 
Cost. Many young adults regardless of gender reported that expense was a key factor in their decision making process when shopping. Prepacked fruit or exotic produce, smoothies and fruit and vegetables sold at local convenient stores were viewed as particularly costly and therefore not purchased.

I suppose I would eat more fruit if it wasn't so expensive. If you go for something more exotic than an apple it tends to get a bit pricey. [Focus group 3, male] Some participants did report overcoming this barrier though by buying fruit and vegetables that were on offer.

It does make it much easier to purchase it if it is buy one get one free in terms of money. [Focus group 2, female]

Time/convenience. Due to busy lifestyles and the perceived lengthy process of buying, preparing and cooking fruit and vegetables, participants reported time as a barrier to the consumption of fruit and vegetables.

Yeah, I mean it usually takes around about 45 minutes before you start serving it up which doesn't sound like a lot of time but when you get in at like half past seven that's quarter past eight before you've even started eating. [Focus group 3, male]

Relatedly, both male and female participants also mentioned lack of convenience when preparing fruit and vegetables. The net effect was an increasing reliance on convenience foods, which often did not include fruit or vegetables. 
Takes a long time as well if you're going to like chop up vegetables and you're really tired and had a long day. It's just so much easier to stick something in the oven. [Focus group 1, female]

Encouragingly though, to overcome this barrier some participants did report the use of specific convenience methods such as pre-packed or frozen vegetables which enabled them to consume fruit and vegetables in an easy, fast manner.

Cooking skills. A lack of cooking skills was another barrier to the consumption of fruit and vegetables expressed by both male and female participants. The preparation of fruit and vegetables, judging their ripeness and quality, and the unfamiliarity of certain produce were all seen as areas where current skills were poor.

I just can't cook. Anything that goes in the oven, you read the box it says the gas mark, it says the time, it comes out and you eat it. That's about as far as my cooking goes. [Focus group 4, male]

Sensory issues. While a range of views regarding the sensory qualities of various fruits and vegetables were discussed, those with negative evaluations reported taste and the perishable nature of fruit and vegetables as key determinants in their preference for other foods.

I've just worked it into my head that it's going to taste gross and I've always associated bad tastes with fruit and veg. [Focus group 1, female]

Think fruit has a problem that it has a short shelf life. You can't just come back to it two weeks later. [Focus group 4, male] 
Planning skills. Finally, male participants alone reported a lack of planning skills as a barrier to consuming more fruit and vegetables.

Everyday you don't plan to go to Morrisons or Asda [leading UK supermarkets] and say right I'm going to eat five fruit and vegetables today. It just doesn't work like that. [Focus group 4, male]

\section{Discussion}

The present qualitative study provides key insights into young adults' understanding of the Department of Health's 5 A DAY message. Most of the young adults self-reported consuming less fruit and vegetables than the recommended five portions a day. This is consistent with national data indicating that young adults (aged 16-24) consume too few fruit and vegetables (Joint Health Surveys Unit, 2008). Furthermore, in accordance with previous studies, (Keim et al., 1997; Johansson and Andersen, 1998; Uglem et al., 2007) male participants reported consuming fewer fruit and vegetables than females. In contrast to previous research though, (Eisner et al., 1992; Anderson et al., 1994b; Dixon et al., 2004) all participants in the current focus groups were aware that the recommended amount of fruit and vegetables to be consumed every day was five portions. However, whilst encouraging, this finding is tempered by the fact that participants displayed confusion concerning the details of the 5 A DAY message (e.g. what constitutes a portion size, what fruit and vegetables count towards one of the 5 A DAY).

While Murphy and Segan (1994) previously reported that young adults generally doubted the need to increase their vegetable consumption, the current study revealed that males alone expressed this view. Males also reported disbelief towards the benefits of consuming five portions of fruit and vegetables a day. Females on the other hand strived to consume the 
recommended amount. This gender difference could be partially attributed to the fact that while women have strong beliefs in nutrition and healthy eating (Biloukha and Utermohlen, 2001) males are less concerned with health issues (Kiefer et al., 2005). A major drawback of the 5 A DAY message in persuading men to consume more fruit and vegetables may therefore be its current focus on eating 'more fruit and vegetables to reduce the risk of disease' which may be seen as irrelevant to males.

Males, unlike females, also reported a lack of motivation towards consuming fruit and vegetables. Von Bothmer and Fridlund (2005) similarly found that female students were more motivated towards a healthy lifestyle, which included changing dietary habits. The lack of motivation displayed by males to consume fruit and vegetables could be linked to wider cultural beliefs surrounding food whereby some foods are associated with 'maleness' such as red meat and alcohol whereas fruit and vegetables are foods connected to women (O'Doherty and Holm, 1999). The reluctance shown by males in the present study to consume fruit and vegetables may therefore be a method of distancing themselves from a food group that they consider feminine (Gough, 2007).

It is a real concern that young male adults continue to report disbelief and a lack of motivation to eat more healthily. These could possibly be the largest barriers that young student males face to consuming fruit and vegetables and the most important to try and reduce because as Dibsdall, Lambert, Bobbin and Frewer (2003) point out, if an individual does not acknowledge there is a problem, no dietary improvement can be made. However, due to the resistance males displayed in the focus groups towards the 5 A DAY message, it seems unlikely that a simple educational intervention alone will be enough to effect behaviour change. Rather a technique is required which promotes a more receptive, open-minded appraisal of health 
messages in this group. Self affirmation - that is engaging in an activity that makes salient important values or attributes - may be one such approach. Self affirmation theory (Steele, 1988) asserts that if individuals can reflect upon an important value or skill, their overall sense of self-worth will be secured, which then allows them to respond to information without resorting to defensive biases. Encouragingly, self affirmation has been shown to promote less defensive responses to health information (Reed and Aspinwall, 1998; Sherman et al., 2000) including the message to eat at least five portions of fruit and vegetables daily (Epton and Harris, 2008). Therefore, self-affirmation prior to a healthy eating message may have the potential to provide a simple yet powerful route by which fruit and vegetable consumption can be increased in young men.

As reported in previous research, (Eisner et al., 1992; Brug et al., 1995; Treiman et al., 1996; Balch et al., 1997; Lea et al., 2005) findings from the focus groups indicated that most participants, regardless of gender, associated a diet rich in fruit and vegetables with positive health benefits. However, the benefits towards appearance and skin, which were exclusively reported by female participants, have not been reported before. These findings suggest that generic healthy eating campaigns may be limited, and that more focused and targeted approaches to encouraging fruit and vegetable consumption are needed.

The barriers identified in the current focus groups were generally reported by both male and female young adults. While moving away from home to start university is known to be associated with declines in fruit and vegetable consumption in young adults (Papadaki et al., 2007) it was surprising that young adults experienced living in halls as a barrier to consuming fruit and vegetables. Clearly they felt that this was limiting their ability to choose the varieties of fruit and vegetables that they preferred to consume. However, based on visits to student catering 
facilities and detailed analyses of their menus, it seems likely that this perception reflects a lack of appropriate nutritional knowledge and motivation rather than an actual lack of choice. Many of the other barriers raised were consistent with those raised in previous studies using different populations. Thus, cost of fruit and vegetables was reported as a barrier, although unlike some other factors, the perception that fruit and vegetables are expensive has some basis in fact, as following a healthy diet rich in fruit and vegetables has been found to be more expensive than an unhealthy one with low levels (Cade et al., 1999).

A lack of cooking skills was also cited as a barrier to the consumption of fruit and vegetables by both males and females. Caraher, Dixon, Lang and Carr-Hill (1999) conducted a study into the state of cooking skills in England and found that only $24.4 \%$ of females and $7 \%$ of males felt confident to cook with basic ingredients. This skill shortage likely reflects the removal of home economics from the National Curriculum in England and Wales, which has led to a reduction in 'hands-on' learning (Furey et al., 2000). Consistent with previous research (Murphy and Segan, 1994) young adults reported that their fruit and vegetable behaviour was also dominated by their busy lifestyle which, along with a lack of cooking skills, meant that they relied on convenience foods such as readymade meals. This convenience culture may be a product of social and environmental factors such as eating alone and eating in front of the television, which are known to be negatively associated with fruit and vegetable intake (Thompson et al., 1999; Brug et al., 1995). Therefore when trying to put into effect practical advice to increase fruit and vegetable intake, young adults should be encouraged to cook and eat together as this may produce a more conducive eating environment. Collectively these findings also illustrate the need for future research to focus on developing ways to deliver advice and guidance on basic cooking skills to this group. 
In the present study, sensory factors, especially taste acted as a barrier to the consumption of fruit and vegetables. This is consistent with a study of Dutch adults that found that when looking at 'satisfaction' beliefs, tasting good was an essential prerequisite for fruit and vegetable consumption (Brug et al., 1995). Therefore encouraging young adults that fruit and vegetables can be tasty is important if their intake is to be increased. Anderson et al (1994a) found that participants favoured familiar vegetables and were 'wary' of new varieties. A difficulty in changing taste perceptions may therefore be that some individuals are food neophobic, that is reluctant to eat novel or unfamiliar foods (Pliner and Hobden, 1992; Tuorila et al., 2001). As rejection can be overcome by repeated exposure to and consumption of novel foods (Koivisto Hursti and Sjoden, 1997) tasting sessions with young adults at university would be a simple technique for encouraging uptake of novel fruit and vegetables.

The only gender specific barrier was regarding the lack of necessary planning skills reported by males. This may be because adolescent males are involved in fewer cooking tasks compared to females (Molaison et al., 2005) and therefore as young adults, males may have not developed the necessary planning skills.

When exploring attitudes towards health behaviours in young adults generally, and university students in particular, it is important to consider the role of peer influence. In mainstream culture, unhealthy dietary behaviour is traditionally associated with university students (Huang et al., 1994; Soriano et al., 2000; Anding et al., 2001; Steptoe et al., 2002; Mammas et al., 2004; Racette et al., 2005). Indeed, Louis et al (2007) reported that those who hold a strong student identity and perceive eating unhealthily as normative are more likely to intend to eat unhealthily. However, while aware of this group norm, there was little evidence in the current focus groups that participants felt influenced by peers that endorsed this norm. The 
current study at least suggests that factors such as convenience and cost are more important barriers preventing eating healthily than peer pressure.

As both media and marketing play a significant role in establishing cultural norms, any initiatives designed to reduce barriers to consuming fruit and vegetables will need to take account of the pervasive media-driven culture in which young adults live (White et al., 2009). Specifically, consumers are inundated with advertisements and persuasive messages from multiple sources which encourage the consumption of unhealthy foods (Byrd-Bredbenner and Grasso, 1999; Kuribayashi et al., 2001; Adams and White, 2009). Alongside this, poor branding and promotion of fruit and vegetables due to inadequate advertising budgets (Mintel, 2001) means that consumers view fruit and vegetables as boring and old fashioned (Anderson et al., 1994b). This situation has not been helped by the often conflicting and confusing healthy eating messages that consumers are exposed to (Mintel, 2009). Although the nationwide government initiative Change4Life, which began in January 2009 has tried to address some of these issues (Department of Health, 2009), it is likely to have a limited effect on young adults as it is not specifically targeted at this demographic group. In the longer term it is clear that more skilful and coordinated marketing efforts will be required to raise both the profile and attractiveness of fruit and vegetables to this consumer group.

Several methodological limitations need to be considered when interpreting these findings. Firstly, the study sample comprised young adults who volunteered to participate in the focus groups and may therefore have had a greater interest in fruit and vegetable consumption than their non-participating peers. Secondly, as young adults entering tertiary education, this group might be expected to have a better all-round knowledge base than other young adults. Thus caution is required in generalizing these findings to the wider population of young adults in 
the UK. Nonetheless, it is sobering that the reported fruit and vegetable intake and associated healthy eating knowledge even in this well educated cohort of young adults is so poor. Finally, an inherent problem with any focus group study is that the data collected may be biased by dominant participants. However this was minimised in the present study through appropriate planning and skilful moderating.

\section{Conclusion}

Overall, although awareness of the 5 A DAY message is high, the current findings suggest that individuals have a poor understanding of its detail. This may explain the current gap between awareness of the 5 A DAY campaign and action. Simply put, young adults' knowledge is not sufficiently detailed to inform or direct behaviour. Coupled with a formidable range of remaining barriers, and questionable attitudes in young males in particular, the study serves to underscore the urgent need to develop more focused and targeted approaches to encourage fruit and vegetable consumption in young adults. In terms of awareness, the 5 A DAY message has been an unqualified success, now comes the tricky part - imparting the knowledge, skills and tools to promote stable and long lasting behavioural change.

\section{References}

Adams, J. \& White, M. (2009) Socio-economic and gender differences in nutritional content of foods advertised in popular UK weekly magazines. European Journal of Public Health, 19, 144-149. 
Agudo, A., Slimani, N., Ocké, M. C., Naska, A., Miller, A. B., Kroke, A., Bamia, C., Karalis, D., Vineis, P., Palli, D., Bueno-de-Mesquita, H. B., Peeters, P. H. M., Engeset, D., Hjartåker, A., Navarro, C., Garcia, C. M., Wallström, P., Zhang, J. X., Welch, A. A., Spencer, E., Stripp, C., Overvad, K., Clavel-Chapelon, F., Casagrande, C. \& Riboli, E. (2002) Consumption of vegetables, fruit and other plant foods in the European Prospective Investigation into Cancer and Nutrition (EPIC) cohorts from 10 European countries. Public Health Nutrition, 5, 1179-1196.

Anderson, A. S., Lean, M. E. J., Foster, A. \& Marshall, D. (1994a) Ripe for change: Fruit and vegetables in Scotland - current patterns and potential for change. Health Bulletin, 52, 5164.

Anderson, A. S., Marshall, D., Lean, M. \& Foster, A. (1994b) Five a day? Factors affecting fruit and vegetable consumption in Scotland. Nutrition \& Food Science, 5, 14-16.

Anding, J. D., Suminski, R. R. \& Boss, L. (2001) Dietary intake, body mass index, exercise and alcohol: Are college women following the dietary guidelines for Americans? Journal of American College Health, 49, 161-171.

Balch, G. I., Loughrey, K., Weinberg, L., Lurie, D. \& Eisner, E. (1997) Probing consumer benefits and barriers for the national 5 a day campaign: Focus group findings. Journal of Nutrition Education, 29, 178-183.

Biloukha, O. O. \& Utermohlen, V. (2001) Healthy eating in Ukraine: Attitudes, barriers and information sources. Public Health Nutrition, 4, 207-215.

Brug, J., Debie, S., van Assema, P. \& Weijts, W. (1995) Psychosocial determinants of fruit and vegetable consumption among adults: Results of focus group interviews. Food Quality and Preference, 6, 99-107. 
Buttriss, J., Stanner, S., McKevith, B., Nugent, A. P., Kelly, C., Phillips, F. \& Theobald, H. E. (2004) Successful ways to modify food choice: Lessons from the literature. Nutrition Bulletin, 29, 333-343.

Byrd-Bredbenner, C. \& Grasso, D. (1999) A comparative analysis of television food advertisements and current dietary recommendations. American Journal of Health Studies, 15, 169-180.

Cade, J., Upmeier, H., Calvert, C. \& Greenwood, D. (1999) Costs of a healthy diet: Analysis from the UK Women's Cohort Study. Public Health Nutrition, 2, 505-512.

Caraher, M., Dixon, P., Lang, T. \& Carr-Hill, R. (1999) The state of cooking in England: The relationship of cooking skills to food choice. British Food Journal, 101, 590-609.

Department of Health (2007) 5 A DAY portion table. Retrieved January 8th 2008, http://www.dh.gov.uk/en/Policyandguidance/Healthandsocialcaretopics/FiveADay.

Department of Health (2009) Change4Life - Eat Well, Move More, Live Longer. Retrieved January 7 th 2010 , http://www.dh.gov.uk/en/News/Currentcampaigns/Change4life/index.htm.

Dibsdall, L. A., Lambert, N., Bobbin, R. F. \& Frewer, L. J. (2003) Low-income consumers' attitudes and behaviour towards access, availability and motivation to eat fruit and vegetables. Public Health Nutrition, 6, 159-168.

Dixon, H., Mullins, R., Wakefield, M. \& Hill, D. (2004) Encouraging the consumption of fruit and vegetables by older Australians: An experiential study. Journal of Nutrition Education and Behavior, 36, 245-249.

Eisner, E., Loughrey, K., Hadley, L. \& Doner, L. (1992) Understanding benefits and barriers to fruit and vegetable consumption. Bethesda, MD, National Cancer Institute. 
Epton, T. \& Harris, P. R. (2008) Self-affirmation promotes health behavior change. Health Psychology, 27, 746-752.

Food Standards Agency (2007) Consumer attitudes to food standards: Wave 7 UK report. London, Food Standards Agency.

Food Standards Agency (2008) Consumer attitudes to food standards: Wave 8 UK report. London, Food Standards Agency.

Furey, S., Mcllveen, H., Strugnell, C. \& Armstrong, G. (2000) Cooking skills: A diminishing art? Nutrition and Food Science, 30, 263-266.

Georgiou, C. C., Betts, N. M., Hoerr, S. L., Keim, K., Peters, P. K., Stewart, B. \& Voichick, J. (1997) Among young adults, college students and graduates practiced more healthful habits and made more healthful food choices than did nonstudents. Journal of the American Dietetic Association, 97, 754-759.

Gough, B. (2007) 'Real men don't diet': An analysis of contemporary newspaper representations of men, food and health. Social Science \& Medicine, 64, 326-337.

Hampl, J. S. \& Sass, S. (2001) Focus groups indicate that vegetable and fruit consumption by food stamp-eligible Hispanics is affected by children and unfamiliarity with nontraditional foods. Journal of the American Dietetic Association, 101, 685-687.

Howarth, C. C. (1991) Dietary intake and nutritional status among university undergraduates. Nutrition Research, 11, 395-404.

Huang, Y. L., Song, W. O., Schemmel, R. A. \& Hoerr, S. M. (1994) What do college students eat? Food selection and meal pattern. Nutrition Research, 14, 1143-1153. 
Johansson, L. \& Andersen, L. F. (1998) Who eats 5 a day?: Intake of fruits and vegetables among Norwegians in relation to gender and lifestyle. Journal of the American Dietetic Association, 98, 689-691.

John, J. H. \& Ziebland, S. (2004) Reported barriers to eating more fruit and vegetables before and after participation in a randomized controlled trial: A qualitative study. Health Education Research, 19, 165-174.

Joint Health Surveys Unit (2008) Health Survey for England 2007, Volume 1 - Healthy lifestyles: Knowledge, attitudes and behaviour. London, The Stationery Office.

Joshipura, K. J., Hu, F. B., Manson, J. E., Stampfer, M. J., Rimm, E. B., Speizer, R. E., Colditz, G., Ascherio, A., Rosner, B., Spiegelman, D. \& Willett, W. C. (2001) The effect of fruit and vegetables on risk for coronary heart disease. Annals of Internal Medicine, 134, 1106-1114.

Kamphuis, C. B. M., van Lenthe, F. J., Giskes, K., Brug, J. \& Mackenbach, J. P. (2007) Perceived environmental determinants of physical activity and fruit and vegetable consumption among high and low socioeconomic groups in the Netherlands. Health \& Place, 13, 493-503.

Keim, K. S., Stewart, B. \& Voichick, J. (1997) Vegetable and fruit intake and perceptions of selected young adults. Journal of Nutrition Education and Behavior, 29, 80-85.

Kiefer, I., Rathmanner, T. \& Kunze, M. (2005) Eating and dieting differences in men and women. The Journal of Men's Health \& Gender, 2, 194-201.

Koivisto Hursti, U.-K. \& Sjoden, P. (1997) Food and general neophobia and their relationship with self-reported food choice: Familial resemblance in Swedish families with children of ages 7-17 Years. Appetite, 29, 89-103. 
Krebs-Smith, S. M., Heimendinger, J., Patterson, B. H., Subar, A. F., Kessler, R. \& Pivonka, E. (1995) Psychosocial factors associated with fruit and vegetable consumption. American Journal of Health Promotion, 10, 98-104.

Kuribayashi, A., Roberts, M. C. \& Johnson, R. J. (2001) Actual nutritional information of products advertised to children and adults on Saturday. Children's Health Care, 30, 309 322.

Lea, E., Worsley, A. \& Crawford, D. (2005) Australian adult consumers' beliefs about plant foods: A qualitative study. Health Education \& Behavior, 32, 795-808.

Louis, W., Davies, S., Smith, J. \& Terry, D. (2007) Pizza and pop and the student identity: The role of referent group norms in healthy and unhealthy eating. Journal of Social Psychology, 147, 57-74.

Mammas, I., Bertsias, G., Linardakis, M., Moschandreas, J. \& Kafatos, A. (2004) Nutrients intake and food consumption among medical students in Greece assessed during a clinical nutrition course. International Journal of Food Sciences and Nutrition, 55, 17-26.

Marshall, D., Anderson, A., Lean, M. \& Foster, A. (1995) Eat your greens: The Scottish consumer's perspective on fruit and vegetables. Health Education Journal, 54, 186-197.

Mintel (2001) Fresh fruit and vegetables. London, Mintel International Group Limited.

Mintel (2009) Media and Food. London, Mintel International Group Limited.

Molaison, E. F., Connell, C. L., Stuff, J. E., Yadrick, M. K. \& Bogle, M. (2005) Influences on fruit and vegetable consumption by low-income black American adolescents. Journal of Nutrition Education and Behavior, 37, 246-251. 
Murphy, M. \& Segan, C. (1994) Young people and their barriers to increasing vegetable consumption: A report of focus group discussions. FNP - FnV Report No. 4. Melbourne, Australia, Centre for Behavioural Research in Cancer.

Naska, A., Vasdekis, V. G. S., Trichopoulou, A., Friel, S., Leonhauser, I. U., Moreiras, O., Nelson, M., Remaut, A. M., Schmitt, A., Sekula, W., Trygg, K. U. \& Zajkas, G. (2000) Fruit and vegetable availability among ten European countries: How does it compare with the 'five-a-day' recommendation? British Journal of Nutrition, 84, 549-556.

Nicklas, T. A., Myers, L., Reger, C., Beech, B. \& Berenson, G. S. (1998) Impact of breakfast consumption on nutritional adequacy of the diets of young adults in Bogalusa, Louisiana: Ethnic and gender contrasts. Journal of the American Dietetic Association, 98, 14321438.

O'Doherty, J. K. \& Holm, L. (1999) Preferences, quantities and concerns: Socio-cultural perspectives on the gendered consumption of foods. European Journal of Clinical Nutrition, 53, 351-359.

Paisley, J., Sheeshka, J. \& Daly, K. (2001) Qualitative investigation of the meanings of eating fruits and vegetables for adult couples. Journal of Nutrition Education, 33, 199-207.

Paisley, J. \& Skrzypczyk, S. (2005) Qualitative investigation of differences in benefits and challenges of eating fruits versus vegetables as perceived by Canadian women. Journal of Nutrition Education and Behavior, 37, 77-82.

Papadaki, A., Hondros, G., Scott, J. A. \& Kapsokefalou, M. (2007) Eating habits of university students living at, or away from home in Greece. Appetite, 49, 169-176.

Pliner, P. \& Hobden, K. (1992) Development of a scale to measure the trait of food neophobia in humans. Appetite, 19, 105-120. 
Racette, S. B., Deusinger, S. S., Strube, M. J., Highstein, G. R. \& Deusinger, R. H. (2005) Weight changes, exercise, and dietary patterns during freshman and sophomore years of college. Journal of American College Health, 53, 245-251.

Reed, M. B. \& Aspinwall, L. G. (1998) Self-affirmation reduces biased processing of health-risk information. Motivation and Emotion, 22, 99-132.

Reicks, M., Randall, J. L. \& Haynes, B. J. (1994) Factors affecting consumption of fruits and vegetables by low-income families. Journal of the American Dietetic Association, 94, 1309-1311.

Sherman, D. A. K., Nelson, L. D. \& Steele, C. M. (2000) Do messages about health risks threaten the self? Increasing the acceptance of threatening health messages via selfaffirmation. Personality and Social Psychology Bulletin, 26, 1046-1058.

Soriano, J. M., Molto, J. C. \& Manes, J. (2000) Dietary intake and food pattern among univeristy students. Nutrition Research, 20, 1249-1258.

Steele, C. M. (1988) The psychology of self-affirmation: Sustaining the integrity of the self. IN Berkowitz, L. (Ed.) Advances in Experimental Social Psychology. New York, Academic Press.

Steptoe, A., Wardle, J., Cui, W., Bellisle, F., Zotti, A. M. \& Baranyai, R. (2002) Trends in smoking, diet, physical exercise, and attitudes toward health in European university students from 13 countries 1990-2000. Preventive Medicine, 35, 97-104.

Thompson, R. L., Margetts, B. M., Speller, V. M. \& McVey, D. (1999) The health education authority's health and lifestyle survey 1993: Who are the low fruit and vegetable consumers? Journal of Epidemiological and Community Health 53, 294-299. 
Treiman, K., Freimuth, V., Damron, D., Lasswell, A., Anliker, J., Havas, S., Langenberg, P. \& Feldman, R. (1996) Attitudes and behaviors related to fruits and vegetables among lowincome women in the WIC program. Journal of Nutrition Education, 28, 149-156.

Tuorila, H., Lähteenmäki, L., Pohjalainen, L. \& Lotti, L. (2001) Food neophobia among the Finns and related responses to familiar and unfamiliar foods. Food Quality and Preference, 12, 29-37.

Uglem, S., Frolich, W., Stea, T. H. \& Wandel, M. (2007) Preferences and perceptions of personal vegetable consumption: A study among young men in the Norwegian national guard. International Journal of Food Sciences and Nutrition, 48, 1-12.

von Bothmer, M. I. K. \& Fridlund, B. (2005) Gender differences in health habits and in motivation for a healthy lifestyle among Swedish university students. Nursing \& Health Sciences, 7, 107-118.

White, P., Sharp, V., Darnton, A., Downing, P., Inman, A., Strange, K. \& Garnett, T. (2009) Food Synthesis Review: A report to the Department for Environment, Food and Rural Affairs. The Social Marketing Practice et al. London, Defra.

Williams, C. (1995) Healthy eating: Clarifying advice about fruit and vegetables. British Medical Journal, 310, 1453-1455.

World Cancer Research Fund/American Institute for Cancer Research (2007) Food, nutrition, physical activity, and the prevention of cancer: A global perspective. Washington, DC, American Institute for Cancer Research.

World Health Organisation (2003) Diet, nutrition and the prevention of chronic diseases: A report of a joint WHO/FAO expert consultation. WHO technical report series (916). Geneva, Switzerland. 
